\title{
Endoscopic transpapillary biopsy using a self-assembled device: the tunnel technique
}

Endoscopic transpapillary biopsy under fluoroscopic control is a well-established method for tissue sampling in the case of biliary stenosis during endoscopic retrograde cholangiopancreatography (ERCP). Nevertheless, some adverse events and technical challenges, especially in proximal strictures, have been reported [1]. Cholangioscopy-guided biopsy remains an expensive, niche technique with small-sized forceps, making histological analysis difficult [2]. Finding a safe, cost-effective technique for histology remains a challenge. Herein we report a new technique for transpapillary biopsy using a biliary dilation catheter.

A 77-year-old patient was referred to our center in September 2019 for cholangitis. The patient underwent a computed tomography (CT) scan and magnetic resonance imaging (MRI), revealing stenosis of the left intrahepatic duct. ERCP confirmed the left biliary stenosis ( Fig. 1), but results from brushing the stenosis were inconclusive. Three days later, a second attempt at ERCP was performed. To obtain adequate tissue specimens for histopathological analysis, the tunnel technique was applied.

An 11.5-Fr biliary dilation catheter was used as the tunnel for the biopsy forceps after cutting the tapered tip, leaving the dilator's radiopaque marker as a reference point. Biliary cannulation was obtained, and the 11.5-Fr tapered catheter was advanced over a guidewire and a $6-\mathrm{Fr}$ catheter, in the left biliary duct, close to the stricture ( $\mathbf{F i g} \mathbf{2}$ ). Following removal of both the guidewire and 6-Fr inner catheter, the 7-Fr biopsy forceps with 7-mm-wide cups were inserted inside the 11.5-Fr catheter ( $\triangleright$ Fig. 3 ). Multiple biopsies were easily performed on the stricture (\Fig.4). No adverse events were recorded. Histology was positive for cholangiocarcinoma and hepatic resection was scheduled.

The tunnel technique for transpapillary biopsies appears to be a non-expensive,

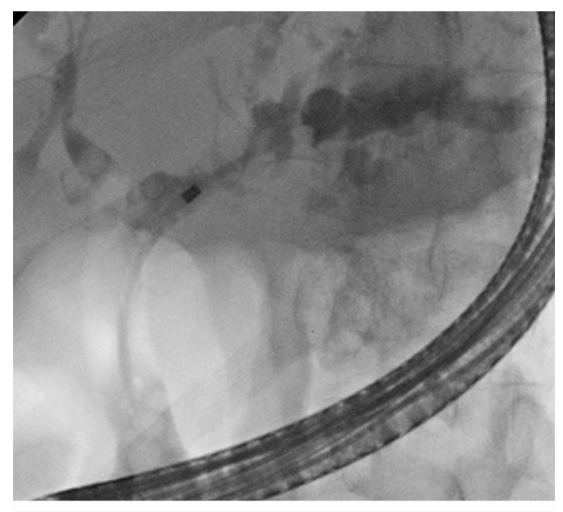

- Fig. 1 Cholangiogram showing a left intrahepatic biliary stenosis.

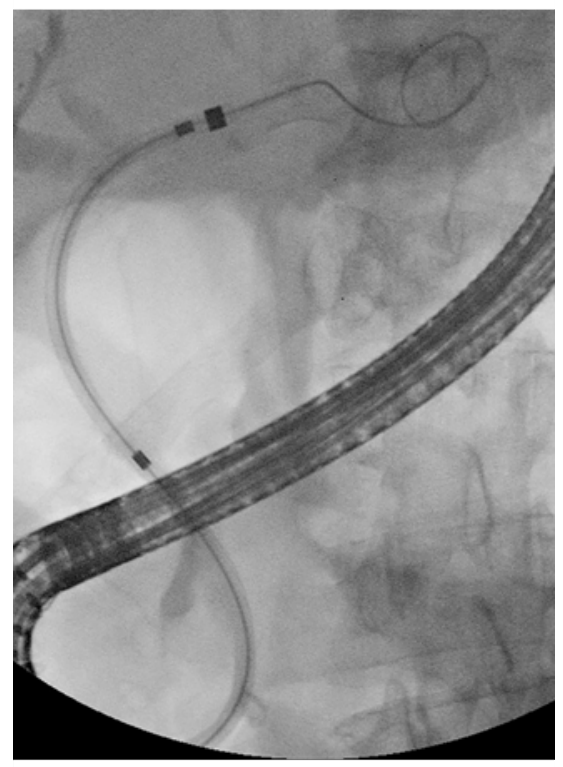

Fig. 2 Fluoroscopic image of an 11.5- $\mathrm{Fr}$ biliary dilation catheter advanced, after cutting the tapered tip, over a 6-Fr catheter and a 0.035 -inch guidewire

safe method, associated with a low risk of biliary injuries likely as a result of advancing the forceps inside a protective tunnel. By using standard forceps, adequate tissue sampling might be obtained

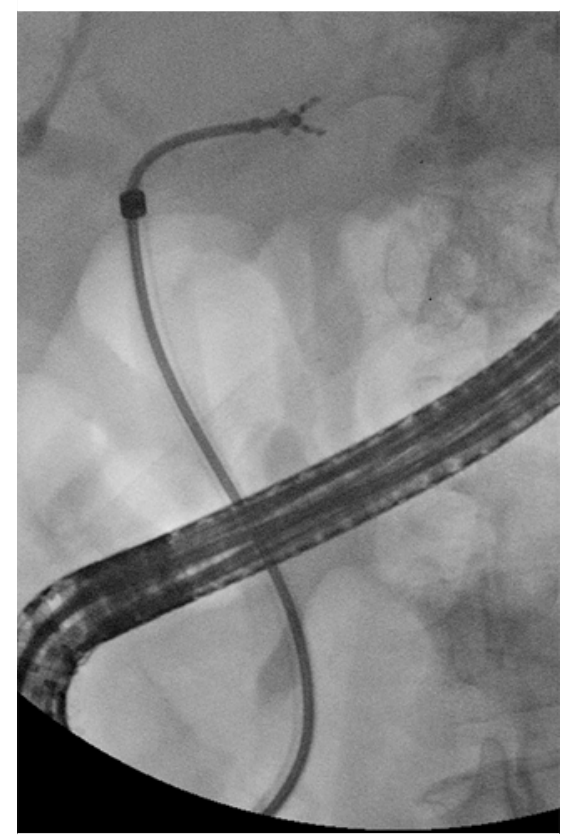

- Fig. 3 The tunnel technique: fluoroscopic image of 7-Fr biopsy forceps advanced inside an $11.5-\mathrm{Fr}$ biliary dilation catheter after cutting the tapered tip.

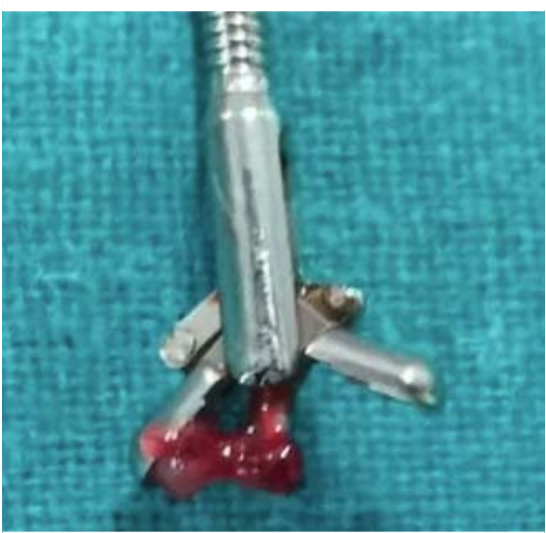

Fig. 4 Biopsy specimen for histopathological analysis obtained with 7-Fr biopsy forceps with 7-mm-wide cups.

during fluoroscopy-assisted biopsies. Further studies are needed to validate this method for biliary stenoses.

Endoscopy_UCTN_Code_TTT_1AR_2AD 


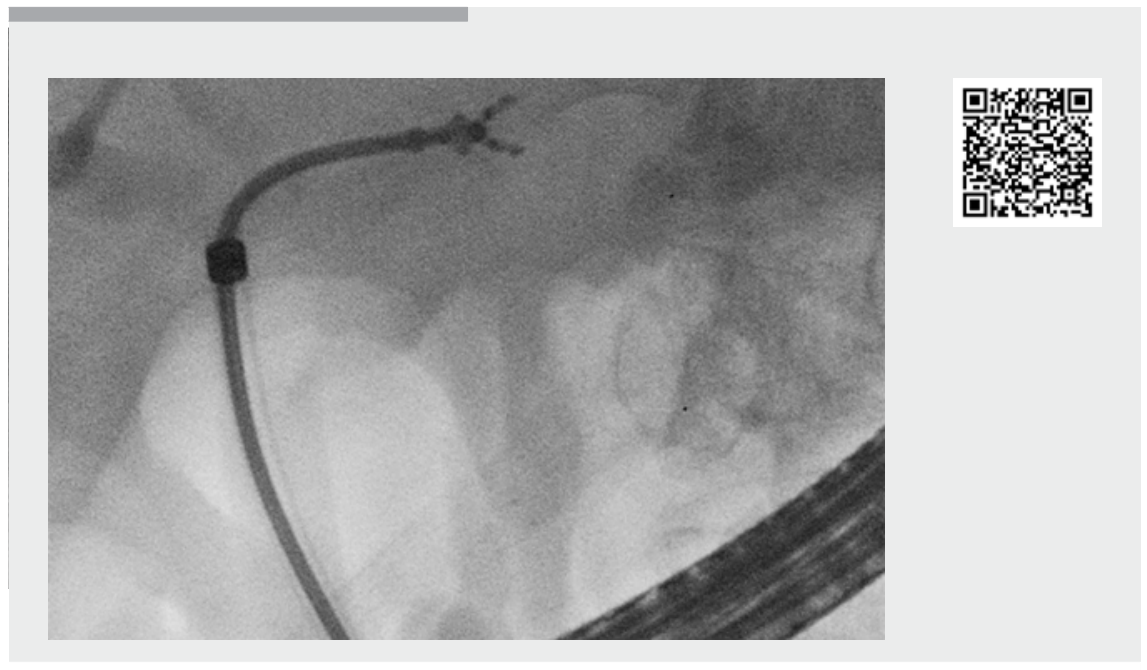

$\checkmark$ Video 1 Application of the tunnel technique for endoscopic transpapillary biopsy of a stenosis in the left intrahepatic duct.

\section{Competing interests}

Andrea Tringali was a consultant for Boston Scientific Corp.

Ivo Boškoski is a consultant for Apollo Endosurgery.

Guido Costamagna has received grant/research support from Olympus Japan, is a member of advisory committees or review panels for Cook, Inc., Boston Scientific Corp., and Taewoong Medical, Inc., and has been a speaker and teacher for Boston Scientific, Corp., and Given Imaging.

\section{The authors}

Vincenzo Perri ${ }^{1,2}$, Beatrice Orlandini ${ }^{1,2}$, Andrea Tringali ${ }^{1,2}$, Ivo Boškoski ${ }^{1,2}$, Guido Costamagna ${ }^{1,2}$

1 Fondazione Policlinico Universitario Agostino Gemelli IRCCS, Digestive Endoscopy Unit, Rome, Italy

2 Centre for Endoscopic Research Therapeutics and Training (CERTT), Università Cattolica del Sacro Cuore di Roma, Rome, Italy

\section{Corresponding author}

\section{Andrea Tringali, MD}

Fondazione Policlinico Universitario Agostino Gemelli IRCCS, Digestive Endoscopy Unit, Largo Gemelli 8, 00168 Rome, Italy Fax: +390630157220

andrea.tringali@unicatt.it

\section{References}

[1] Chen WM, Wei KL, Chen YS et al. Transpapillary biliary biopsy for malignant biliary strictures: comparison between cholangiocarcinoma and pancreatic cancer. World J Surg Oncol 2016; 14: 140

[2] Pereira P, Vilas-Boas F, Peixoto A. How SpyGlass ${ }^{\text {TM }}$ May Impact Endoscopic Retrograde Cholangiopancreatography Practice and Patient Management. GE Port I Gastroenterol 2018; 25: 132-137

\section{Bibliography}

DOI https://doi.org/10.1055/a-1089-7315

Published online: 29.1.2020

Endoscopy 2020; 52: 616-617

(c) Georg Thieme Verlag KG

Stuttgart · New York

ISSN 0013-726X

\section{ENDOSCOPY E-VIDEOS}

https://eref.thieme.de/e-videos

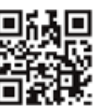

Endoscopy E-Videos is a free access online section, reporting on interesting cases and new techniques in gastroenterological endoscopy. All papers include a high quality video and all contributions are freely accessible online.

This section has its own submission website at https://mc.manuscriptcentral.com/e-videos 